\title{
Relationship between thyrotropin and cortisol levels in euthyroid obese subjects
}

Neslihan Soysal Atile1, Betül Ekiz Bilir1, Bülent Bilir2, Sonat Pınar Kara2

1 Tekirdag State Hospital, Endocrinology Department, Tekirdag, Turkey

2Namık Kemal University Faculty of Medicine, Internal Medicine Department, Tekirdag, Turkey

Several studies have reported that thyrotropin (TSH) is positively correlated with obesity, dyslipidemia and impaired glucose metabolism even in normal range limits. We aimed to evaluate the TSH levels in a cohort of otherwise healthy obese women without clinical evidence of hypothyroidism.

127 female patients were enrolled in this study. Anthropometric and laboratory measurements were retrospectively analyzed. Patients were divided into subgroups according to body mass indices (BMI).

\begin{tabular}{|c|c|c|c|}
\hline Group (BMI kg/m2) & $\mathrm{n}$ & TSH & Cortisol \\
\hline $0(18,0-24,9)$ & 18 & $2,06 \pm 0,29$ & $14,63 \pm 1,15$ \\
\hline $1(25,0-29,9)$ & 16 & $1,71 \pm 0,26$ & $14,46 \pm 0,82$ \\
\hline $2(30,0-34,9)$ & 29 & $1,96 \pm 0,16$ & $13,94 \pm 0,73$ \\
\hline $3(35,0-39,9)$ & 25 & $1,81 \pm 0,26$ & $13,39 \pm 0,89$ \\
\hline $4(40,0-44,9)$ & 20 & $2,16 \pm 0,19$ & $15,59 \pm 0,96$ \\
\hline $5(>45)$ & 19 & $1,83 \pm 0,25$ & $14,14 \pm 1,01$ \\
\hline
\end{tabular}

Groups were age-matched. No statistically significant correlation was found between TSH and BMI, HOMA-IR, trigliseride, HDL or LDL values. But a significant positive correlation between TSH and cortisol levels was revealed $(p=0,000)$. As expected, HOMA-IR and trigliseride values were positively, HDL levels were negatively correlated with BMI $(p<0,05)$.

In our euthyroid cohort, we did not found any significant association between plasma thyrotropin levels and obesity However, the positive relationship between TSH and cortisol is a compelling finding. It's known that overt hypothyroidism is associated with frankly elevated cortisol levels. But our study finding suggested a correlation within normal range limits and requires further investigations in order to better understand the mechanisms involved in the TSH-cortisol relationship.

\footnotetext{
1-Walter KN, Corwin EJ, et al. Elevated thyroid stimulating hormone is associated with elevated cortisol in healthy young men and women. Thyroid Research. 2012;5:13

2-Samuels MH. Effects of variations in physiological cortisol levels on thyrotropin secretion in subjects with adrenal insufficiency: a clinical research center study. J Clin Endocrinol Metab. 2000;85:1388-93
} 